\title{
Defaulting at the Nigerian National Neuropsychiatric Hospital
}

\author{
M. L. ADELEKAN, Department of Behavioural Sciences, University of Ilorin, Ilorin, \\ Nigeria; and A. O. OGUNLESI, Senior Consultant Psychiatrist, Aro Neuropsychiatric \\ Hospital and WHO Collaborating Centre for Research and Training in Mental \\ Health, PMB 2002, Abeokuta, Nigeria (correspondence)
}

Defaulting from out-patient surveillance constitutes a major problem among neuropsychiatric patients globally. In an extensive review of default studies (Baekeland \& Lundwall, 1975), it was concluded that between $20-50 \%$ of psychiatric patients fail to return after their first visit and $31-56 \%$ attend not more than four times before defaulting.

In Nigeria the few available studies have merely highlighted the existence of the problem and speculated on possible associated factors (Odejide $e t$ al, 1978; Makanjuola, 1985). To date, there is no Nigerian study which has attempted to interview defaulters about the possible reason(s) for their defaulting, despite the need for such health service research, especially in developing countries. It is relevant to acknowledge the difficulties that are inherent in interviewing defaulters at home in Nigeria. Such difficulties include lack of essential facilities (transport/personnel), long distance of patients' homes from health institutions, chaotic numbering system of housing units, high populace mobility and a poorly developed communication network (Ojesina, 1979).

In the light of the above-mentioned constraints, rather than interviewing defaulters at home, we decided to employ a modified approach to the study of the subject. A group of defaulters who reported in the hospital after a specified period of default were interviewed and compared with a matched control of "defined" non-defaulters seen within the study period on certain parameters. The aim is to identify some significant factors associated with defaulting in such patients and this will guide health planners in providing a better and more cost effective health service at this period of dwindling economic resources.

\section{The study}

The study was carried out at the out-patient department of the Nigerian National Neuropsychiatric Hospital and WHO Collaborating Centre for Research and Training in Mental Health, Aro, Abeokuta for one month (November 1987). All consecutive defaulters who turned up for treatment during the month of study were screened. An earlier pilot study showed that the average default period (calculated from the date of first missed appointment to the date of current assessment) was 15 months. A 'defaulter' in this study was therefore taken to include only those whose default period was equal to or greater than this cut-off point of 15 months. Only 69 out of the 120 defaulters seen during this month of study satisfied this criterion and constituted the study sample.

This group of 69 'defined defaulters' were interviewed by us both, assisted by two research assistants. A specially designed pro forma was used to collect information on background sociodemographic and clinical data, case note diagnosis (broad categories only) and the reasons for defaulting. A control group of 'non defaulters' were defined as patients who have consistently complied with their out-patient appointments within the 15 months before the date of assessment. In addition, they must also have attended the out-patient department at least four times during the 15 month period. The 69 consecutive defaulters were matched for age, sex and case note diagnosis (broad categories only) with the control group of non defaulters and both were interviewed with the pro forma described above.

\section{Findings}

The study sample and the controls were essentially identical in age, sex and case note diagnoses as shown in Table I.

Fifteen defaulters were single (16 controls), 42 were married ( 33 controls) and 12 were separated/ divorced or widowed (20 controls). The differences did not reach statistical significance.

Twenty-nine defaulters had no formal education ( 26 controls), 23 had primary school education only (21 controls), 16 had secondary school education (18 controls) and 1 had post secondary education (4 controls). The differences were not statistically significant.

About $90 \%$ each of the defaulters and controls were in the low skilled/low income bracket. 
TABLE I

Background data on the study and control groups

\begin{tabular}{lcc}
\hline Characteristic & $\begin{array}{c}\text { Defaulters } \\
(\mathrm{n}=69)\end{array}$ & $\begin{array}{c}\text { Non-defaulters } \\
(\mathrm{n}=69)\end{array}$ \\
\hline Sex & Male 24(34.8\%) & $\begin{array}{c}\text { Male 25(36.2\%) } \\
\text { Female 44(63.8\%) }\end{array}$ \\
$\begin{array}{l}\text { Age at time of study } \\
\text { (mean } \pm \text { s.d.): years }\end{array}$ & Female 45(65.2\%) & $38.2 \pm 13.3$ \\
$\begin{array}{l}\text { Diagnostic composition** } \\
\text { (i) Schizophrenic illness }\end{array}$ & $37.6 \pm 13.4$ & $49(71 \%)$ \\
(ii) Affective Psychoses & $49(71 \%)$ & $9(13 \%)$ \\
(iii) Neurotic illness & $9(13 \%)$ & $4(6 \%)$ \\
(iv) Epilepsy & $4(6 \%)$ & $7(10 \%)$ \\
\hline
\end{tabular}

**Only broad (case-note) diagnoses were used.

TABLE II

Comparison of defaulters and non-defaulters on some parameters

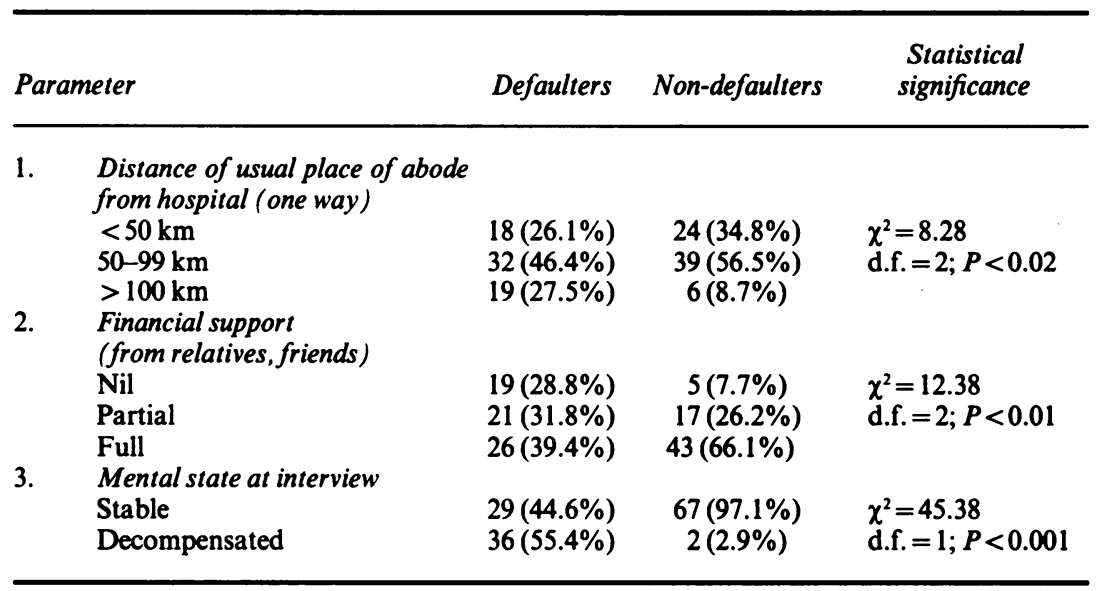

Thirty-five (50.7\%) of both the defaulters and controls were employed during the period of study while 34 of each $(49.3 \%)$ were not employed during this period.

The means \pm s.d. of the duration of illness from index illness (months) for the defaulters and controls were $105.3 \pm 66.6$ and $111.6 \pm 71.1$ respectively. The difference was not statistically significant.

When the cost (transport and drugs) incurred by each defaulter and control during the penultimate hospital visit was estimated, 41 defaulters spent less than 50 naira (as against 47 controls), 21 spent between 50-100 naira (19 controls) and 4 spent over 100 naira ( 2 controls). The differences did not reach statistical significance ( $\mathbf{N} 10=1$ pound sterling).
The statistically significant results obtained from the comparison between defaulters and controls are shown in Table II.

Some of the reasons given by defaulters for non attendance included "no money for follow up"-34.8\%; "no relative to bring patient"$18.8 \%$; "work or other commitment prevented attendance" - $15.9 \%$; "relapsed and tried alternative medicine" $-11.6 \%$.

\section{Comments}

The commonest reason given by the defaulters in this study was financial difficulty. Although the amount spent per hospital visit (including transportation and 
drugs) failed to differentiate defaulters from non defaulters, the former seemed to be worse off as they were less likely to receive financial support from family or friends. About one out of every five defaulters also indicated that they had no relatives to bring them to the hospital. The latter findings agree with those of an earlier study (Ojesina, 1979) which observed that the usually resourceful extended family set up in Nigeria can be overstretched financially and exhausted physically as well as emotionally in caring for its unfortunate chronically disabled neuropsychiatric members. We therefore suggest that in view of the potentially chronic nature of their disability coupled with their low productivity and the consequent stress on the extended family set-up, government should substantially subsidise the treatment of these patients as well as make available a monetary allowance for the families of patients certified as genuinely impecunious and unable to afford the current high costs of treatment.

The other factor that was significant in this study was the distance of usual place of abode from the hospital. Although seven out of every ten of these patients tended to travel 50 kilometres or more to get to the hospital, defaulters as a group were significantly more likely to travel 100 kilometres or more. This may complicate the pressures on the already overburdened relatives. We therefore wish to suggest the need to decentralise some of the existing psychiatric facilities by increasing their community orientation such that services are provided for the people in facilities nearer their domicile. The onus is therefore on mental health professionals to advise government on this issue, now that government is embarking on the process of integrating mental health into the existing primary health care scheme. The gains of such an approach should certainly eliminate the need for patients to travel a long distance for follow-up.

One limitation of this study lies in the selection of the study sample (defaulters), five out of every ten of whom had mentally decompensated at the time of presentation/interview. Therefore one can infer that they presented because of an impending or a fullblown relapse. This group therefore may not be fully representative of the population of defaulters. Although the present approach by the authors represents an improvement on previous studies (Odejide et al, 1978; Makanjuola, 1985), there is still a need to interview defaulters in the community prospectively and such a study could be made more comprehensive, for example by examining the personality characteristics of defaulters, their levels of social anxiety/social withdrawal, severity of presenting illness and other relevant factors. The results of such a study should further provide more useful information to mental health service planners on how to minimise the major problem of defaulting among neuropsychiatric patients.

\section{References}

Bafkeland, F. \& Lundwall, L. (1975) Dropping out of treatment: a critical review. Psychological Bulletin, 82, 738-783.

Makanuola, R. O. A. (1985) Cinical and socio-cultural parameters in Nigerian psychiatric patients: a prospective study. Acta Psychiatrica Scandinavica, 72, 512-521.

Odejide, A. O., Olatawura, M. O. \& Makanjuola, R. O. A. (1978) A psychiatric service in a Nigerian general hospital. African Journal of Psychiatry, 4, 97-102.

OJEsINA, J. O. (1979) Some social and psychological problems of schizophrenics in Nigeria. African Journal of Psychiatry, 5, 97-101. 